\title{
Abuse Against School Girls as a Predictor of their Psychosocial Wellbeing in Western Oromiya Regional State, Ethiopia
}

\author{
Melkamu Afeta Gonfa* and M.V.R.Raju** \\ *PhD Scholar, Department of Psychology and Parapsychology, College of Arts and Commerce, Andhra \\ University \\ **Professor, Department of Psychology and Parapsychology, College of Arts and Commerce,Andhra University
}

\begin{abstract}
The present study main purpose was to examine abuse against school girls as a predictor of their psychosocial wellbeing in the Western Parts of Oromiya Regional State, Ethiopia. Cross-sectional research study design was employed to collect the quantitative data from the target population. 592 female students were selected from upper primary schools (grade 5 to 8 ) of the East Wallagga and Horro Guduru Wallagga zones through purposive and simple random sampling techniques. Participants' age category ranges from 10 to 19 years of age. ISPCAN Child Abuse Screening Tool: Children's Version (ICAST-CH) and the original $\mathrm{M}_{2}$ Victimization scale developed by Nadel, Spellmann and etal. (1991) was used to examine girls' exposure to the different types of abuses. Moreover, the Friedman Wellbeing Scale (FWBS) was adopted to measure the psychosocial wellbeing of school girls. Data gained from survey questionnaire was analyzed by using descriptive statistics, t-test, correlation and multiple linear regression analysis. The obtained result indicated that an average of $36.0 \%$ of girls was found out to be abused in three settings (home, school and community). The correlation result reveals that there was a moderate positive association between father's age and family size with abuse. However, mothers` age, parents' monthly income and parents` substance abuse were found out to be inversely related with abuse. The different types of abuse were significantly predicted the psychosocial wellbeing of school girls in a negative direction.
\end{abstract}

Key words: Prevalence, Child abuse, Violence and Psychosocial Wellbeing

\section{I.INTRODUCTION}

International Society for the Prevention of Child Abuse and Neglect and the World Health Organization Consultation on Child Abuse Prevention (1999) defined child and adolescents girls abuse as maltreatments that constitutes all forms of physical, psychological and sexual abuse, neglect, labor and commercial exploitation resulting in actual or potential harms to the child's health, survival, development or dignity in the context of a relationship of responsibility, trust or power. The National Commission United Kingdom (1996) also explained abuse in terms of violence against children and adolescents at home and in institutional settings like schools and other work places or public organizations. Besides, the UK Commission stated that child abuse incorporates any activity that individuals, institutions or processes do or fail to do which directly or indirectly harms children including girls or damage their prospects of safe and healthy development in to adult hood. For example, absence of the clearly defined and stated policy and legal documents of a certain country is a clear indication of abuse and violence perpetrated against the young generation. Mahider (2008:6) also asserts that abuse takes place in all contexts and settings in which girls find themselves such as family and home, schools, care or residential institutions, work situations, on the streets, in detention prisons in relation to police actions and the use of capital and physical punishments. Studies point out that there are different contributing factors for the causes of abuse and violence against girls. These factors are entrenched in the child`s unique characteristics and its relation with the family members, interaction with the surrounding environments including the macro level variables. The family and school are the main institutions that play crucial roles in shaping children and youngsters toward the desired goals and in socializing them in line with the cultural values and beliefs of their society. But there are cases that these settings become the breeding and perpetuating place of violence targeted against youngsters. Individual characteristics of the child (such as age or stage of development, sex, temperament, substance abuse and disability) and the unique features of the parent or caregiver (such as single parent, mental disorders, dysfunctional family relationship and substance abuse) have also bearing effect on whether girls experience violence in the home and outside environments. In addition, parental low socio economic status, large family size, marital conflict and poor method of parental child disciplining are also other contributing factors for girls' abuse. Other factors also develop from the environment, as in the case of emergency situations, but may also be related to the availability of social networks, or loss of livelihood. At the macro level, World Report on Violence and Health (2002:69-72) stated that the cultural 
values and legislations are contributing for the vulnerability of girls in school settings and in their way in to and out from schools. For instance, the historical tradition of unequal power relations between male and female (that is the belief in inherent superiority of males over females), the wide spread poverty, legislations and cultural sanctions that traditionally denied women and girls an independent legal and social status are some of them. Therefore, violence and abuse is likely to be the outcome of a combination of personal, familial, social, economic and cultural factors and the interrelationship amongst these factors (Newal, 2005: 60-61) .Globally, the primary victims of abuse and violence are children and adolescent girls who are the future fate of any nation. The effects of abuse and violence can be long lasting. It leaves a lasing scar in the mind of the girls and that in turn affects their later developments, adulthood life. Abuse and violence affects not only girls but also the different segments of the society such as parents, family, community and the nation at large. Those abused youngsters may develop anti social or deviant behaviors that affect the wellbeing of all levels of the society. For instance, abused girls may enter in to the life of streets, prostitution, delinquency, and drug and alcohol addiction, developing unsafe sexual behavior and exposed to sexually transmitted diseases like HIV/AIDS. Gradually they become dangerous and even become a burden for the society and their nation at large (Mahider, 2008:5).

The WHO (2002) report reveals that the consequences of girls' abuse contribute a significant portion of the global health, psychological, social and educational problems burden. Health wise it results in physical injuries, cognitive impairment, developmental retardation or delays, death due to harms or injuries, reproductive health problems (those abused sexually) such as genital injuries, unwanted pregnancy due to rape, repeated abortion that causes urinary tract infections. This in turn results for girls in reducing their chance of bearing a normal child or in giving immature birth and infected with sexually transmitted diseases like HIV/AIDS (WHO, 2002:1). Psychologically abused girls experience depression and anxiety, low self esteem, feeling of loneliness, post traumatic stress disorder, sleeping and eating disorders, feeling of self harm and developing suicidal behaviors. Socially abused girls develop poor relationship with significant others like with their parents, family members, equal peers, teachers and with the surrounding community. They also develop poor heterosexual relationship with their partner in their later adult life. Their interaction with other people is weak, passive or conflict ridden. As a result they become stigmatized and discriminated by other people (Mahider, 2008:5-6 \& WHO, 2002:1-2).

\section{Study Objectives}

The main purpose of this study was to examine abuse perpetrated against school girls as a predictor of their psychosocial wellbeing in the Western parts of Oromiya Regional State of Ethiopia. The participants were examined about their experience of abuse at school and its effects on their psychosocial wellbeing.

Specifically the study aims:

* To find out the prevalence rates of abuse or violence against school girls in terms of social institutions.

* To examine the association between participants and parents socio-demographic variables with abuse against school age girls.

* To determine the effects of abuse that is perpetrated against child adolescent girls on their psychosocial wellbeing.

\section{Research Approach and Design}

\section{II.METHODS}

The present study employed cross-sectional research design to examine the prevalence of abuse and its effects on school age girls in East and Horro-Guduru Wallagga zones of Western Oromiya Regional State, Ethiopia. Methodologically, quantitative research approach was utilized. The population was selected from upper primary schools (grade 5 to 8 ) that included female students 10 to 19 years of age category. The male students and child girls below 10 years of age were not incorporated in the study population.

\section{PROCEDURE}

\section{Population, Sample and Sampling Techniques}

The study employed purposive and simple random sampling techniques at different levels in order to select sample participants from the population. In line with this, from the list of 18 Oromiya zones, East Wallagga and Horro Guduru Wallagga zones were selected through purposive sampling technique. Then in the next stage, a sampling frame was constructed for the districts found in two Wallagga zones and from the list of each zone two districts were chosen through purposive sampling techniques by considering the urban and rural settings. Accordingly, five upper primary schools were selected from urban areas and eight upper primary schools were selected from rural areas of both zones through proportional sampling techniques.

Specifically, from East Wallagga zone three schools selected from the urban setting (Naqamte city) while five schools were selected from rural settings through simple random sampling techniques. In addition, from Horro 
Guduru Wallagga zone two schools were selected from the urban center (Shambo city) while four schools were selected from rural settings through simple random sampling techniques as the target of the study population. All upper primary schools grade level (grade 5 to 8 ) and sections were included in the study population. Accordingly, 12 female students were selected from each grade level through simple random sampling techniques.

\section{Sample Size Determination}

The statistical report document from the two Wallagga zones Bureau of Education revealed that the total number of enrolled girl students in the upper primary schools was 98502 in the year 2015/2016. To be more specific, the student girls' population from East Wallagga was 50024 while from Horro Guduru Wallagga was 48478 students. In line with this, sample size of the study population was determined or decided based on the formula developed by the renowned Nigerian statistician Taro Yamane (1967).

$\mathrm{n}=\frac{\mathrm{N}}{1+\mathrm{N}(\mathrm{e})^{2}}$ at $95 \%$ confidence level and 0.05 precision level or sampling error where

$\mathbf{n}=$ the sample size,

$\mathbf{N}=$ the total population size

Based on the above formula the total sample size of 604 female students was selected from the two Wallagga zones. Accordingly, 344 and 260 female students participated in the study from East Wallagga and Horro Guduru Wallagga zones respectively. However, 5 students did not correctly complete the survey questionnaire and their response paper was omitted from the analysis. This means after the data collection was over from 604 female students it was found out that only 599 filled and return the survey questionnaire. In addition, at the time of data feeding to the SPSS program the responses of 7 participants was found out to be incomplete; and then it was excluded from the analysis. Therefore, data analysis and interpretation was conducted on responses from 592 participants.

\section{The Survey Questionnaire}

\section{MATERIALS}

A structured questionnaire was utilized in order to gather the quantitative data from the target population. ISPCAN Child Abuse Screening Tool: Children's Version (ICAST-CH) scale was used to measures respondents' socio-demographic variables. The original $\mathrm{M}_{2}$ Victimization Scale developed by Nadel, Spellmann and etal. (1991) was also used to measure girls' exposure to the different types of abuses. For victimization measure the obtained Cronbach alpha =.98. Moreover, the Friedman Well-being Scale (FWBS) was adopted to measure the psychosocial wellbeing of school girls. It contains 20 bi-polar adjective scales that range from 0 to 10. Here the computed Cronbach alpha value for psychosocial wellbeing measure was .96.

\section{Data Analysis}

Data gained from survey questionnaire was analyzed by using SPSS software version 21.0. Accordingly, Descriptive statistics, Correlation, Mean Comparisons and Multiple linear regression analysis was performed to analyze the data.

\section{IV.RESULTS AND DISCUSSIONS}

\section{Participant Characteristics}

Table 1: Participants' Age * Grade level cross tabulation

\begin{tabular}{|c|c|c|c|c|c|c|c|}
\hline \multicolumn{3}{|c|}{ Variable } & \multicolumn{4}{|c|}{ Grade Level } & \multirow[t]{2}{*}{ Total } \\
\hline & & & Grade 5 & Grade 6 & Grade 7 & Grade 8 & \\
\hline \multirow{4}{*}{$\begin{array}{c}\text { Participants' } \\
\text { Age }\end{array}$} & \multirow[t]{2}{*}{$10-14$} & Count & 105 & 101 & 89 & 15 & 310 \\
\hline & & $\%$ of total & $17.7 \%$ & $17.1 \%$ & $15.0 \%$ & $2.5 \%$ & $52.4 \%$ \\
\hline & \multirow[t]{2}{*}{$15-19$} & Count & 32 & 44 & 64 & 142 & 282 \\
\hline & & $\%$ of total & $5.4 \%$ & $7.4 \%$ & $10.8 \%$ & $24.0 \%$ & $47.6 \%$ \\
\hline \multirow{2}{*}{\multicolumn{2}{|c|}{ Total }} & Count & 137 & 145 & 153 & 157 & 592 \\
\hline & & $\%$ of total & $23.1 \%$ & $24.5 \%$ & $25.8 \%$ & $26.5 \%$ & $100 \%$ \\
\hline
\end{tabular}

From the above table 1 one can observe that participants' age range was between 10 to 19 years. According to WHO definition this age range lies in adolescent period. The first age range category covers early adolescence (teen age period) from10 to 14 years that make up 52.4\% (310), while the second age category includes late adolescence 15 to 19 years that includes $47.6 \%(282)$ of the population. 
Table 2: Descriptive statistics for prevalence of overall abuse and by social institutions $(\mathrm{N}=592)$

\begin{tabular}{|l|l|l|l|c|c|}
\hline \multicolumn{1}{|c|}{ Variables } & Groups & $f$ & $\%$ & $M$ & $S D$ \\
\hline \multirow{2}{*}{ Abuse at School } & Unabused & 368 & 62.2 & 1.38 & .49 \\
\cline { 2 - 4 } & Abused & 224 & 37.8 & & \\
\hline \multirow{2}{*}{ Abuse at Home } & Unabused & 395 & 66.7 & 1.33 & .47 \\
\cline { 2 - 4 } & Abused & 197 & 33.3 & & \\
\hline \multirow{2}{*}{$\begin{array}{l}\text { Abuse in the } \\
\text { Community }\end{array}$} & Unabused & 388 & 65.5 & 1.34 & .48 \\
\cline { 2 - 4 } Over all Abuse & Abused & 204 & 34.5 & & \\
\cline { 2 - 4 } & Unabused & 379 & 64.0 & \multirow{2}{*}{1.64} & .48 \\
\cline { 2 - 4 } & Abused & 213 & 36.0 & & \\
\hline
\end{tabular}

As the above table 2 depicts, the mean prevalence rate of overall total abuse for the three institutions was computed and it reveals that $36.0 \%$ of participants were reported to be abused at three settings $(M=1.64$, $S D=.48$ ) while $64.0 \%$ were reported as they were not abused. Here, even though the mean prevalence rate of abuse is lower than the non abused ones, the rate is still found among countries with higher prevalence rates of abuse in the world. In terms of institutions, $37.8 \%$ of participants were reported to be abused at school $(M=1.38$, $S D=.49), 34.5 \%$ of them were abused in the community $(M=1.34, S D=.48)$ and $33.3 \%$ of them were abused at home $(M=1.33, S D=.47)$. From this one can infer that the overall prevalence rate of the different types of abuse was higher at school than in the community and at home. Abuse in the community represents the second place and home accounts the least prevalence rate. This finding is somewhat similar to the study conducted by African Child Policy Forum(2011:1-3) who stated alarmingly that more than $84 \%$ of girls in Ethiopia have experienced some form of physical abuse and $34 \%$ of them reported to have victims of rape. Despite all legal ratification and protection from the Federal Democratic Republic of Ethiopian (FDRE) constitution, physical abuse, psychological and sexual abuses at home, community and schools is still high and widespread. In schools and educational settings teachers punished more than 90 percent of their students, although 70 percent of teachers are aware of the negative consequences of corporal punishments. Report from children participants themselves revealed that the majority of them had experienced physical abuses at schools. African Child Policy Forum (ACPF) finding also indicates $21 \%$ of urban and $64 \%$ of rural school children reported bruises or swelling on their bodies because of parental punishment. According to the study on Violence against Girls in Ethiopia conducted by Save the Children Sweden in collaboration with Ethiopian Government (2008) respondents reported that physical or corporal punishment is formally forbidden by law in schools but students, teachers and parents are still practicing it. The study findings in Ethiopia by Save the Children, Ministry of Education and Ministry of Women Affairs (2008:50-52) also reported that sexual abuse and violence at home, community and within the school environment are particularly distressing. Mahider (2008:6) also asserts that abuse takes place in all contexts and settings in which girls find themselves such as family and home, schools, care or residential institutions, work situations, on the streets, in detention prisons in relation to police actions and the use of capital and physical punishments. Moreover, the study by UNICEF (2005) stated that as child girls grow and develop in to maturity like adolescent age they spend most of their time outside home and family and they are more vulnerable to abuses by other peoples like older male students, teachers, other staffs in school settings and by people whom they know or by stranger people in their way in to and out of school.

Table 3: Independent t-test for abused and non abused girls $(\mathrm{N}=592)$

\begin{tabular}{|l|l|l|l|l|l|l|}
\hline Characteristics & $N$ & $M$ & $S D$ & $t$ & $d f$ \\
\hline \multirow{2}{*}{$\begin{array}{l}\text { Overall } \\
\text { Abuse }\end{array}$} & Abused & 213 & 1.89 & .41 & 30.96 & 590 \\
\cline { 2 - 7 } & Unabused & 379 & 1.19 & .12 & 24.38 & 233.83 \\
\hline
\end{tabular}

$* \mathbf{p}<0.05, * * \mathbf{p}<0.01$

As indicated in the above table 3, a two way sample t-test assuming equal variance and equal variances not assumed was performed to test the hypothesis that the mean result of the two groups ' was equal. In both cases there was a significance mean difference between the overall abused and non abused groups. Levene`s equality of variances not assumed was considered for its appropriateness since the obtained value is $<0.05$ and it shows that the mean average score of abused girls $(M=1.89, S D=.41, N=213)$ was significantly different from the non abused girls $(M=1.19, S D=.12, \quad N=379), t(233.83)=24.39, p=.000$. From this one can observe that the mean average of abused girls was relatively higher than that of the non abused ones. 
Abuse against School Girls as a Predictor of their Psychosocial Wellbeing in Western Oromiya Regional

Table 4.Independent Sample t-test for inter-parental violence $(\mathrm{N}=592)$

\begin{tabular}{|l|c|c|c|c|c|}
\hline Characteristics & $N$ & $M$ & $S D$ & $t$ & $d f$ \\
\hline $\begin{array}{l}\text { Grew up witnessing inter-parental } \\
\text { violence }\end{array}$ & 199 & 1.59 & .43 & 5.980 & 590 \\
\hline $\begin{array}{l}\text { Not witnessed } \\
\text { inter-parental violence }\end{array}$ & 393 & 1.37 & .41 & 5.912 & 385.85 \\
\hline
\end{tabular}

$* \mathbf{p}<0.05, * * \mathbf{p}<0.01$

As indicated in the above table 4, an independent sample t-test assuming equal variance and equal variances not assumed was performed to test the hypothesis that the mean results of the two groups were equal. The result revealed that there is a significance difference between the mean of those girls grew up witnessing inter-parental conflict and those never witnessed inter-parental conflict. Levene's equality of variance not assumed was also considered and it showed that the mean average score of those adolescent girls grew up while witnessing inter-parental conflict $(M=1.59, S D=.43, N=199)$ was significantly different from those never witnessed inter-parental conflict $(M=1.37, S D=.41, N=393), t(385.85)=5.91, p=.000$. From this one can note that there was a difference between the mean score of girls of the two groups, where the mean of those girls grew up witnessing inter parental conflict was relatively higher than that of the non witnessed ones. This implies that those girls grew up witnessing parental conflict has higher scores on the scale that measures inter parental conflict than the non witnessed ones. Regarding this, the study by Newal (2005:68-70) revealed that in India inter-partner violence at the home doubled the risk of direct violence against children and girls in the household. Those children living in conflict home were at the risk of physical violence themselves and also suffer from psychological and emotional disturbances. For such children psychotherapeutic intervention of their problem should be undertaken timely if not their conditioning may go on to be future perpetrators or lead their life as a victim of violence. Furthermore, those children from conflicting parents develop problems in their external relations such as overwhelmed fear of others and poor interaction with other people. These children may also learn powerful lessons about aggression in interpersonal relationships which they carry with them into their future life. A similar study conducted by UNICEF(2005:8-9) stated that indirect forms of abuses like witnessing violence between parents has been identified as one of contributing factor for psychological or emotional abuse of children. It has severe long-term consequences which may be the most damaging compared to other forms of child maltreatment. The study also pointed out that this aspect of abuse was the most hidden and underestimated form of child maltreatment, and is relatively little researched when compared with physical and sexual abuses

Table 5.Descriptive statistics for parents' socio-demographic characteristics $(\mathrm{N}=592)$

\begin{tabular}{|l|l|l|}
\hline Variables & $M$ & $S D$ \\
\hline Father's Age & 47.07 & 9.902 \\
\hline Mother's Age & 38.81 & 7.886 \\
\hline Parents Monthly Income & 1125.1182 & 707.578 \\
\hline Family Size & 6.68 & 1.827 \\
\hline Parents`Substance Abuse level & 2.8159 & .3540 \\
\hline Total Abuse & 1.4425 & .4310 \\
\hline
\end{tabular}

The above table 5 stated that the socio-demographic characteristics of the parents. Participants reported that the average score of fathers` age was $(M=47.07, \mathrm{SD}=9.90)$ and for the mothers` age was $(M=38.81, S D$ =7.89). The result implies that the mean age of fathers` was relatively higher than that of the mothers`age. It also indicated that fathers ' have higher age score on the scale that measures abuse. The average monthly income of the respondents' parent was $(M=1125.12, S D=707.58)$, while the average score for the parent family size was $(M=7, S D=1.83)$. From this one can infer that parents have low monthly income to support a large family size. This is because on a daily basis the parent has 37.50 birr (\$1.44) to feed on seven family members. Besides, participants' reported that the mean average of parents' extent of substance consumption level $(M=2.82$, $S D=.35)$. 
Table 6.Parents`characteristics correlation with the overall abuse $(\mathrm{N}=592)$.

\begin{tabular}{|l|l|l|l|l|l|l|l|}
\hline \multicolumn{2}{|l|}{ Variables } & $\begin{array}{l}\text { Father's } \\
\text { Age }\end{array}$ & $\begin{array}{l}\text { Mother's } \\
\text { Age }\end{array}$ & $\begin{array}{l}\text { Parents } \\
\text { Income }\end{array}$ & $\begin{array}{l}\text { Family } \\
\text { Size }\end{array}$ & $\begin{array}{l}\text { Parents } \\
\text { Substance } \\
\text { Abuse }\end{array}$ & $\begin{array}{l}\text { Overall } \\
\text { Abuse }\end{array}$ \\
\hline \multirow{2}{*}{$\begin{array}{l}\text { Father's } \\
\text { Age }\end{array}$} & $r$ & & & & & & \\
\hline & Sig. & & & & & & \\
\hline $\begin{array}{l}\text { Mother's } \\
\text { Age }\end{array}$ & $\mathrm{r}$ & $.760^{* * *}$ & & & & & \\
\hline & Sig. & .000 & & & & & \\
\hline $\begin{array}{l}\text { Parents } \\
\text { Income }\end{array}$ & $\mathrm{r}$ & $-.099^{*}$ & -.067 & & & & \\
\hline & Sig. & .016 & .101 & & & & \\
\hline $\begin{array}{l}\text { Family } \\
\text { size }\end{array}$ & $\mathrm{r}$ & $.119^{* *}$ & $.113^{* * *}$ & $-.223^{* *}$ & & & \\
\hline & Sig. & .004 & .006 & .000 & & & \\
\hline $\begin{array}{l}\text { Parents } \\
\text { Substance } \\
\text { Abuse }\end{array}$ & $\mathrm{r}$ & -.046 & -.057 & $.160^{* * *}$ & -.067 & & \\
\hline & Sig. & .262 & .163 & .000 & .105 & & \\
\hline $\begin{array}{l}\text { Total } \\
\text { Abuse }\end{array}$ & $\mathrm{r}$ & .046 & -.011 & $-.213^{* * *}$ & $.144^{* * *}$ & $-.190^{* * *}$ & \\
\cline { 2 - 8 } & Sig. & .264 & .797 & .000 & .000 & .000 & \\
\hline
\end{tabular}

\footnotetext{
$* \mathbf{p}<0.05, * * \mathbf{p}<0.01(2$-tailed)
}

Pearson correlation was computed whether there was an association among predictor variables of parental socio-demographic variables such as parental income, family size and substance abuse level with the abuse of school girls. The observed correlation reveals that there was significant linear relationship between variables: fathers`age, mothers`age, parents`income, family size and parents substance abuse and overall abuse and their associations are $\mathrm{r}(0.46)=0.000, p<0.05, \mathrm{r}(-.011) 0.000, p<0.05, \mathrm{r}(-.213)=0.000, p<0.05, \mathrm{r}(.144)=0.000$, $\mathrm{p}<0.05$ and $\mathrm{r}(-.190)=0.000, \mathrm{p}<0.05$ respectively. From this one can infer that there was a weak positive correlation of variables such as father's age and family size with the abuse of child adolescent girls. But the association of family size to the abuse is higher than that of the association of fathers' age with abuse. It indicated that as family size increases the more the child adolescent girls' vulnerability to the different types of abuses. In addition, the result of positive association of the fathers age with abuse is inconsistent with the previous findings. Studies indicated that young parents are more likely to abuse their children than the older ones because they experience challenges and stresses in fulfilling the responsibility of childrearing and supporting. On the other hand, there was a weak negative (inverse relationship) correlation of variables such as mothers`age, parents' monthly income and parents' substance abuse with abuse of child adolescent girls. However, the correlation of parental monthly income with abuse was relatively higher than that of the correlation of parents` substance abuse and the mothers`age with abuse. Moreover, from the three variables mothers`age has a very poor correlation with overall abuse. In line with this, World Report on Violence and Health (2002:11) and Newal (2005:68-69) also stated that physically violent parents are also more likely to be young, single and poor. Moreover, single parent households are substantially more likely to have incomes below the poverty line. Hence, single parents having lower income and carrying the sole burden of family responsibilities including the absence of or the presence of fewer supports contribute to the high rate of maltreating children. The study by Mahider (2008:6) also indicated that young parents are more likely to abuse their children than the older ones because they experience challenges and stresses in fulfilling the responsibility of childrearing and supporting. Mahider further pointed out that parental low socio economic status, large family size, marital conflict and poor method of parental child disciplining are also other contributing factors for girls' abuse. The unique features of the parent or caregiver such as single parent, mental disorders, dysfunctional family relationship and substance abuse have also bearing effect on whether girls experience abuse and violence in the home and outside.

Elliot and Woodward (2007) stated that before computing multiple regressions collinarity of the variables should be checked. In Pearson correlation it is assumed that there is no evidence of multi collinearity if a bivariate correlation coefficient between the two predictor variables was found to be below 0.80. Gujarati (2003) on the other hand stated that to detect multi collinearity between independent variables Variance Inflation Factor (VIF) should be computed. Theoretically, a VIF greater than 10 may suggest that the explanatory variable is multi collinear with each other. In this study after calculating the collinearity of the predictor variables, the result indicated that the mean average VIF for all variables was 5.60. Hence, there was no evidence of indication of collinearity between explanatory variables. 
In line with this, in the current study multiple linear regression analysis was performed to determine that to what extent measures of the different types of abuse or violence predict the psychosocial wellbeing of the school girls. The computed regression result is here under.

Table 7: Model Summary $b$ for abuse types and psychosocial wellbeing

\begin{tabular}{|c|c|l|l|l|}
\hline Model & $\mathrm{R}$ & $\mathrm{R}$ Square & Adjusted R Square & Std. Error of the Estimate \\
\hline 1 & $.714^{\mathrm{a}}$ & .510 & .507 & .3214 \\
\hline
\end{tabular}

The above table 7 revealed model summery for multiple regression. As you observe it the computed regression result indicates that the $R^{2}$ is 0.51 . This shows that the three types of abuse measures as a group accounts $51.0 \%$ of the variation and it significantly predicted psychosocial wellbeing $\mathrm{F}(3,591)=$ $203.854, p=.000)$. The remaining contribution might be attributed to residual factors.

Table 8: Regression coefficient ${ }^{\text {a }}$ for abuse types and psychosocial wellbeing

\begin{tabular}{|c|c|c|c|c|c|c|c|}
\hline \multirow{2}{*}{\multicolumn{2}{|c|}{ Model }} & \multicolumn{2}{|c|}{$\begin{array}{l}\text { Un standardized } \\
\text { Coefficients }\end{array}$} & \multirow{2}{*}{$\begin{array}{c}\text { Standardized } \\
\text { Coefficients } \\
\text { Beta }\end{array}$} & \multirow[t]{2}{*}{$\mathrm{t}$} & \multicolumn{2}{|c|}{$\begin{array}{l}\text { Collinearity } \\
\text { Statistics }\end{array}$} \\
\hline & & $\mathrm{B}$ & SE & & & Tolerance & VIF \\
\hline \multirow[t]{4}{*}{1} & (Constant) & 3.348 & .067 & & 50.016 & & \\
\hline & Physical abuse & -.436 & .064 & -.279 & -6.841 & .502 & 1.993 \\
\hline & $\begin{array}{l}\text { Psychological } \\
\text { Abuse }\end{array}$ & -.379 & .040 & -.387 & -9.567 & .508 & 1.967 \\
\hline & Sexual Abuse & -.183 & .045 & -.152 & -4.108 & .608 & 1.644 \\
\hline
\end{tabular}

$* \mathrm{p}<0.05, * * \mathrm{p}<0.01$

As it is indicated in the above table 8 , the beta coefficients of the three types of abuse measures as a group were examined in their ability to explain the outcome variable (psychosocial wellbeing). The obtained result indicates that all predictor variables contributed significantly to the variance in the dependent variable in the negative direction $(t=50.016 ; p=.000)$. On the other hand, beta weights were computed to determine the relative contribution of each predictor variables to the variance explained. Thus, psychological abuse measures contributed highly and significantly to the variance in the psychosocial wellbeing measure in the negative direction $(t=-9.567, B=-.387, p=.000)$. This is followed by physical abuse that contributed significantly to the variance in a negative direction $(\mathrm{t}=-6.841, B=-.279, \mathrm{p}=.000)$, while the least one is sexual abuse that also contributed significantly to the variance in a negative direction $(t=-4.108, B=-.152, p=.000)$.

\section{V.CONCLUSIONS}

The present study reveals that child and adolescent girls in Ethiopia, particularly in the study area have been experiencing high levels of abuse and violence in all the settings: at home, school and in the community. Pearson correlation also revealed that there is a moderate positive association between father`s age and family size with the abuse of girls. However, mothers` age, parents' monthly income and parents` substance abuse level were found out to be inversely related with abuse. The different types of abuse were found out to be negatively affecting the psychosocial wellbeing of school girls. Hence, the researcher calls for all concerned bodies (government, non government and other stakeholders) to work collaboratively in an attempt to curb and fight abuse and violence perpetrated against school age girls. It necessitates an attitudinal shift and awareness creation at all societal levels. Creating a society that disproves and condemns abuse and violence acts and behaviors at all settings; family, school, community, work places and other public areas is needed. It also implies the need for much attention from government and policy makers in enforcing and implementing the existing laws for the effective protection of child and girls right in all settings. On the other hand, most of the previous studies about abuse against children including girls were giving emphasis to the capital city, Addis Ababa (Finfinne) and regional state capitals of the country. Nonetheless, the current study was conducted in zonal areas so that all stake holders can use it as an input in their attempt to take remedial action or tackling the pervasive problem. It provides baseline information for the interested researchers in the study area and opens the way for further in depth study that encompasses all age levels of child and adolescent girls on abuse and violence or the related issues in different regional areas of the country. 


\section{REFERENCES}

[1]. World Report on Violence and Health (2002). Child Abuse and Neglect by Parents and Other Care Givers.

[2]. Mahider, B. (2008).Child Abuse and Neglect: An Alternative policy Solutions in Ethiopia: Ethiopian Social Policy reader V.1., Addis Ababa University, Addis Ababa.

[3]. Save the Children UNICEF and Ministry of Women and Child Development Government of India (2007). Study on Child Abuse: India 2007, New Delhi.

[4]. World Health Organization (2002).Child Abuse and Neglect: http://www.int/violence- Injury-prevention.

[5]. Child Welfare Information Gateway (2004). Protecting Children and Strengthening Families: A bulletin for Professionals (2004), Risk and Protective Factors for Child Abuse and Neglect.

[6]. UNICEF (2005).Violence Against Children in Europe, For Every Child Health, Education, Equality, Protection and Advance Humanity: Preliminary Review of Research.

[7]. UNICEF Innocent Research Center and the Government of the Netherlands (2009).A study on Violence Against Girls: Report on the International Girl Child Conference, The Hague.

[8]. UN Report (2006).Violence Against Children in the Home and Family.

[9]. Newal, P. (2005).Editorial Board of the UN Secretary General`s Study on Violence Against Children in the Home and Family.

[10]. UNICEF (2006). Violence against Children in School and Educational Settings.

[11]. ACPF (2011).Violence Against Children in Africa: A compilation of the Major Findings of the Various Research Projects Conducted by the African Child Policy Forum.

[12]. African Child Policy Forum (2006).Born to be a High Risk: Synthesis information from three sources.

[13]. Save the Children Sweden Regional Office for Eastern and Central Africa (2010).A Study on Child Protection Mechanisms in Ethiopia.

[14]. What Factors Contribute to Child Abuse and Neglect. https://WWW. Child Welfare Gov/pubs/foundation M.cf Sexual abuse.

[15]. Gujarati, D. (2004).Basic Econometrics $4^{\text {th }}$ edt. The McGraw Graw.Hill Company.

[16]. Elliot, A. Woodward, W. (2007).Statistical Analysis: Quick Reference Guide Book with SPSS Examples. New Delhi: Sage Publications, Inc. 